\title{
O HUMOR EM RUÍNAS EM FIM DE PARTIDA
}

\author{
Tauan Fernandes Tinti
}

tauantinti@gmail.com

1.

"no symbols where none intended" é a curiosa frase que encerra Watt, novela imediatamente anterior à chamada "trilogia do pós-guerra", que, ao lado de Esperando Godot, garantiu notoriedade a Samuel Beckett. Retirada de seu contexto, a frase passa a conjurar um campo de forças que oscila entre a aporia e a piada disparatada, revelando um pequeno abismo lógico sempre a ressurgir em sua obra: se não devemos tomar como símbolo o que não foi planejado como tal, essa intenção externa ao texto permanece inacessível por definição ${ }^{1}$, dificilmente servindo

1. Esse tipo de postulado teórico se mostra particularmente verdadeiro no caso de Beckett, autor notoriamente avesso a interpretar seus próprios textos, a não ser que seja para negar uma interpretação proposta por outrem. Na biografia Damned to Fame, James Knowlson relata várias ocasiões em que Beckett assumiu tal postura, sendo talvez a mais memorável sua reação a Adorno: “Adorno insistiu que 'Hamm' derivava de 'Hamlet'. Ele tinha toda uma teoria baseada nisso. Beckett disse 'Desculpe-me, professor, mas não pensei em Hamlet quando inventei esse nome'. Mas Adorno insistiu, e Beckett ficou um pouco irritado... À noite, Adorno começou sua fala e, é claro, ressaltou que 'Hamm' derivava de 'Hamlet'. Beckett ouviu muito pacientemente. Mas ele então cochichou no meu ouvido - "Esse é o progresso da ciência, que professores possam seguir em frente com seus erros!” (UNSELD, citado por KNOWLSON, 1996, p.428) 
como bússola interpretativa; de outro lado, fica sugerida a existência de símbolos, mas definitivamente não confirmada, pois não se exclui a possibilidade de que nenhum tenha sido planejado. Confrontada com a série de elementos enigmáticos de uma peça como Fim de Partida, qualquer tentativa de interpretação é atravessada por esse movimento dialético entre a significação e sua negação sumária, cristalizando a ideia de que o texto se encontra sempre um passo à frente de seu leitor. Levada ao limite, a indecisão tornada mecanismo interno desvela-se como disparate, piada - talvez de mau gosto - tanto sobre a leitura, incapaz de alcançar qualquer certeza, quanto sobre a própria obra, que se vê sob a ameaça de simplesmente não fazer nenhum sentido.

Mesmo diante dessa perspectiva desanimadora, leitores e espectadores continuam a rir das criações de Beckett, em desacordo com a ideia de que uma mesma piada contada muitas vezes acaba por perder seu encanto. Ao contrário, em casos como o de Esperando Godot ela só parece aumentar: de acordo com James Knowlson (1996, p.349 e segs.), os espectadores da primeira montagem da peça, em francês e sob a direção de Roger Blin, não viram muita graça em momentos como a rotina cômica com os chapéus no ato 2, chegando em uma ocasião a abandonar em massa o Théâtre de Babylone durante o monólogo de Lucky, e as primeiras montagens inglesa e americana tiveram destino semelhante. Tal postura diante de qualquer peça de Beckett seria hoje improvável, e a distância que separa as gargalhadas atuais do silêncio desconcertado de outrora não pode ser atribuída unicamente à consagração do autor como “clássico", diante do qual seríamos ideologicamente levados à reverência, rindo sem vontade de todas as suas tiradas ou vendo profundidade em qualquer página em branco por ele deixada. ${ }^{2}$ É justamente esse tipo de ruído semântico que nos impede de tomar a reação dos espectadores como índice puro de movimentos internos do texto, gerando uma inversão de causa e efeito: voltando à frase final de Watt, seria o caso de encarar o riso como um momento de certeza do sentido - trata-se de uma piada, e piadas nos fazem rir - paradoxalmente facilitado pela quantidade de leituras conflitantes que se acumula em torno do autor, ao passo que o momento já passado de desconcerto teria sido sua recusa absoluta. O resultado dessa perspectiva é uma simplificação do humor

2. É claro, essa reverência é algo inegavelmente consolidado, a ponto de poder mesmo ser parodiada em uma "notícia" do jornal satírico The Onion, intitulada "Acadêmicos descobrem 23 páginas em branco que podem também ser uma peça perdida de Samuel Beckett”. Disponível em http://www.theonion.com/articles/scholars-discover-23-blankpages-that-may-as-well,1946/ . 
beckettiano, que passaria desse modo a significar sempre a mesma coisa, sem nos deixar escolha diante de sua aparição, já que riso e silêncio se tornam assim pólos artificialmente estáticos de uma relação que se pretendera dialética. Ao contrário, o conflito que se esboça escapa da delimitação cronológica, não podendo ser reduzido à história de sua recepção - no caso das peças, passando ao largo das particularidades de cada montagem; a indecisão entre as tentativas de significação e seu fracasso é continuamente reencenada e problematizada por Beckett, constituindo-se em ponto fundamental de tensão, e não de alternância. E é exatamente nesse ponto de tensão que se deve situar a hipótese interpretativa a ser aqui investigada, a saber, que Fim de Partida coloca diversos procedimentos do humor em questão de forma altamente destrutiva, e a significação retroativa que seus destroços passam a ter adquirido nesse processo podem ser extrapolados de modo a produzir um pequeno vislumbre, de dentro da própria peça, sobre seu estatuto de obra de arte.

2.

A ideia de que qualquer tentativa de uma interpretação totalizante de Fim de Partida inevitavelmente acaba por se ver frustrada pelas resistências da peça a esse tipo de gesto de apreensão é quase uma unanimidade na crítica - as exceções dignas de nota seriam o livro pioneiro de Martin Esslin (1968, pp.55-68), o Teatro do Absurdo, onde é proposta a leitura relativamente difundida da crise de uma consciência às portas da morte, e um dos textos de John Fletcher (2000, pp.96-113) sobre o drama de Beckett, onde ele afirma que o conteúdo de Fim de Partida é sua própria teatralidade; de outro lado, temos críticos como Hugh Kenner (1996, p.121), autor de poderosas leituras sobre o dramaturgo, que dá voz a esse impasse interpretativo ao dizer que na peça somos constantemente "provocados por pistas de um sistema, deixadas para que não sejam muito seguidas”, enquanto Ruby Cohn (1973, p.142) conclui que, na falta de possibilidades de sentidos subjacentes definidos, é possível apenas que encontremos e estabeleçamos seus padrões estruturais, em um movimento análogo ao de "desemaranhar os fios de um tecido". Por sua vez, Adorno (1985, p.52), em um texto divisor de águas, retoma e expande a questão ao abordá-la em sua relação com "uma mudança no a priori dramático: o sentido metafísico positivo já não é mais possível de forma tão substantiva (se é que de fato já o fora)". Dissipada essa possibilidade, não há como recobrir o vazio ao fundo de Fim de Partida por meio de sua conceituação como absurda em sentido existencialista, restando apenas, como quer Adorno, reconstruir a estrutura de sua significação ausente. 
Trata-se, afinal, de uma recusa que é antes de tudo sistemática, uma espécie de depuração do acúmulo de elementos repetidos, ou melhor, reiterados por meio de variações sutis que se constituem em uma rede de padrões levemente assimétricos composta por pseudo-símbolos.

Como forma refratada dessa postura no plano mais básico do enredo da peça, teríamos as inclinações paranóicas de Hamm, o protagonista pretensamente trágico de Fim de Partida, que exige de seu servo Clov a constante observação do exterior do abrigo onde vivem, como se qualquer possibilidade de aproximação representasse perigo absoluto. Quando, próximo ao desfecho da peça, a expectativa contínua de Hamm dá mostras de se confirmar, o resultado é nada menos que frustrante; com o auxílio da luneta, Clov avista uma criança, e a resposta de Hamm, após o comentário meta-referencial sobre a possibilidade de uma "subtrama" tardia, é "Se ele existe, virá até aqui ou morrerá por lá. E se não existe, não vale a pena." (Fim de Partida, 2002, p.125), e nem mais uma palavra sobre o assunto. Da perspectiva de seu desenlace, o motivo recorrente das idas de Clov às janelas do abrigo tende à auto-anulação, dele restando apenas a sua estrutura, e esse mesmo padrão se reproduz com relação a outros acontecimentos da peça. Procedimento semelhante se dá com os pedidos incessantes de Hamm por seu analgésico, geralmente formulados como "Não está na hora do meu calmante?", e contornados pelas negações moduladas de Clov; finalmente, quando chega o horário tido como correto, ele por fim declara "Não há mais calmante. Você nunca mais vai ganhar seu calmante” (Fim de Partida, 2002, pp.114-115) Se estes exemplos ainda apresentam certo simulacro de lógica que poderia justificar, mesmo insatisfatoriamente, sua repetição, o mesmo não se dá com o non sequitur que encerra uma discussão sobre abrir ou não a janela:

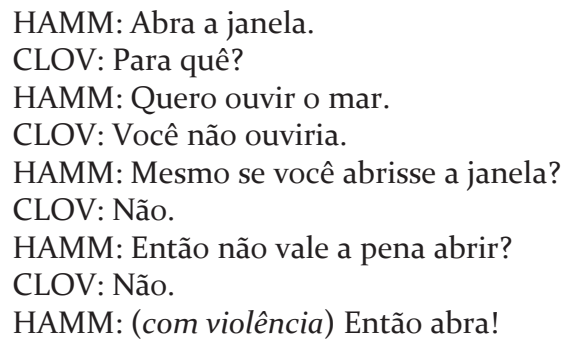

(Fim de Partida, 2002, p.122-123)

O encadeamento aparentemente racional do diálogo é levado ao absurdo nessa última fala de Hamm, que acaba por funcionar como punchline em uma piada que assim isolada não soa de todo distante do humor de vaudeville, fonte inegável de diversos procedimentos das peças de 
Beckett. Sua progressão nesse sentido é impecável, e é na passagem do primeiro para o segundo então que Adorno (1985, pp.72-73) situa um dos centros de gravidade da peça: a validade do ato é aqui inversamente proporcional à sua justificativa, em uma inversão que desvela a própria lógica como falácia, estabelecendo a razão em contraste com um mundo que não se submete integralmente às suas regras. A sobreposição de expectativas frustradas se dá pela via de um acúmulo que nada tem de aleatório, estabelecendo padrões cujas pequenas variações concernentes aos procedimentos lógicos, nos casos acima elencados resultam na contaminação mútua de cada sentido negado, o que por sua vez estabelece uma estrutura reflexiva que visa à total auto-regulação; dito de outra forma, cada uma dessas pequenas falácias lógicas acaba por fazer referência às outras, e não a algo de externo, pois as leis arbitrárias que vigoram no universo de Fim de Partida são aquelas estabelecidas pela própria peça.

Sem dúvida, Fim de Partida não é o primeiro drama a resistir à interpretação, mas talvez seja o primeiro a inscrever essa resistência na superfície de seu texto. É digno de nota para os meus propósitos aqui que essa inscrição seja feita nos termos de uma piada, ainda que dessa vez ela só tenha graça para um de seus personagens, e provavelmente não para os espectadores:

HAMM: O que está acontecendo?

CLOV: Alguma coisa segue seu curso.

Pausa.

HAMM: Clov!

CLOV: (irritado) Que é?

HAMM: Não estamos começando a... a... significar alguma coisa?

CLOV: Significar? Nós, significar! (Riso breve) Ah, essa é boa!

HAMM: Fico cismando. (pausa) Será que um ser racional voltando à terra não acabaria tirando conclusões, só de nos observar? (Assume a voz de uma inteligência superior) Ah bom, agora entendo, agora sei o que eles estão fazendo!) (CLOV sobressalta-se, larga a luneta e começa a coçar a virilha com as duas mãos. Voz normal) Mesmo sem ir tão longe... (emocionado) ...nós mesmos... às vezes... (com veemência) Pensar que isso tudo poderá talvez não ter sido em vão!

(Fim de Partida, 2002, pp.8o-81)

A primeira pausa do trecho separa a repetição de um dos muitos refrões da peça da indagação de Hamm, tomada como disparate por Clov, mas a reincidência do termo something ("alguma coisa", na tradução) na breve troca entre os personagens estabelece um paralelismo que se insere retroativamente no núcleo dos acontecimentos: se alguma coisa segue 
seu curso, definitivamente não se trata da construção de um sentido. A rejeição da ideia por parte de Clov traz algo de enigmático, não permitindo aos espectadores que compartilhem de seu riso, seja este forçado ou não - nos termos de Bergson (1991), seria como se não pertencêssemos à paróquia (dos personagens), e por isso não entendemos qual é a graça. $\mathrm{O}$ pequeno monólogo de Hamm, por sua vez, é modulado pelo histrionismo que caracteriza o personagem - de acordo com Beckett, mesmo "sua segurança é sempre pose” (citado por FLETCHER, 200o, p.111) -, e o grau extremo de autoconsciência de seu status representacional por ele apresentado impede que tomemos literalmente seu desespero, que contradiz diálogos como "CLOV: Vamos parar com esse jogo! // HAMM: Nunca!” (Fim de Partida, 2002, p.121).

A piada não-intencional entre Hamm e Clov, ao incluir de forma deliberada a recusa ao sentido nos limites da própria peça, transforma sua resistência à interpretação também em material dramático, expandindo seu potencial de anti-significação como forma de negar já de antemão as tentativas mais elaboradas de interpretá-la. Mas isso não implica em uma necessária aceitação passiva do nonsense que transborda da peça, pois o resultado desse procedimento desafia a lógica da mesma forma que seus personagens, culminando em um paradoxo: se Fim de Partida se antecipa às nossas tentativas de lhe imprimir sentido ao ponto de negá-lo a priori com a veemência do riso, ele o faz segundo o método paranóico de Hamm, prevenindo-se contra uma ameaça em potencial que é descartada tão logo se concretiza, e, pela repetição desse movimento, fazendo cada vez menos sentido quanto mais tentamos interpretá-la ou melhor, incorporando retroativamente a refutação de cada hipótese interpretativa por meio da construção de padrões estruturais reflexivos cada vez mais complexos, o que faz com que a peça se torne assim um universo cada vez mais auto-regulado. Algo como a piada sobre o queijo suíço, cuja quantidade de furos aumenta proporcionalmente ao seu tamanho, levando à formulação "quanto mais queijo, menos queijo".

3.

De acordo com a tipologia freudiana de $O$ chiste e sua relação com o inconsciente (1905), a maioria dos arremedos de piada aqui trazidos seriam classificados como um subtipo dos chistes tendenciosos denominado chiste cético: a piada que, a despeito da técnica empregada - figuração pelo contrário, contrasenso, etc -, é centrada "no problema das condições da verdade", atacando "a certeza mesma de nosso conhecimento" (2006, p.108-109). Nesse estágio da teoria freudiana, a descarga de energia do riso tem sua fonte de prazer inconsciente descrita como uma rejeição 
da lógica racional por meio de um retorno momentâneo a um estágio anterior à sua consolidação. A aparente contradição decorrente do fato de tal movimento ser possível somente por meio de um trabalho altamente elaborado é característico da complexidade do aparelho psíquico teorizado pelo autor: estágios anteriores de desenvolvimento jamais podem ser considerados superados, podendo sempre vir à tona, mesmo que às vezes apenas momentaneamente. ${ }^{3}$ Levando esse raciocínio adiante, teríamos em Fim de Partida um acúmulo de chistes céticos que produz, por meio de sua interrelação e sobreposição, um ciclo vertiginoso de questionamento acerca das condições de possibilidade da produção de sentido, e esse movimento espiralado não culminaria na máxima descarga de prazer, mas em uma ausência que se coloca aqui como questão. A inserção desses chistes nos movimentos internos da peça configura menos uma regressão do que a constatação de um estado de coisas, pois a ausência de lógica - ou sua substituição pela lógica particular da peça - não fica restrita apenas a esses momentos, mas se deixa entrever a partir deles. A força destrutiva à qual o humor é submetido funciona como uma espécie de corolário à ideia de Adorno (1985, p.51) de que todos os conteúdos da peça são por ela reduzidos a lixo cultural, e esse desgaste é posto em cena de forma explícita em um diálogo entre Nagg e Nell:

NAGG (baixo): Ouviu só? Um coração na cabeça, dele!

Ri abafado.

NELL: Não se ri dessas coisas, Nagg. Por que você sempre tem que rir?

NAGG: Mais baixo!

NELL (sem diminuir o tom de voz): Nada é mais engraçado que a infelicidade, com certeza. Mas...

NAGG (chocado): Ah!

NELL: Sim, sim, é a coisa mais cômica do mundo. E nós rimos, rimos com gosto, no começo. Mas é sempre igual. É, é como uma história engraçada que ouvimos várias vezes: ainda achamos graça, mas não rimos mais.

(Fim de Partida, 2002, pp.57-58)

Do riso abafado e cauteloso de Nagg à sentença de Nell sobre o fim do riso, a decadência que percorre a peça, contaminando todos os seus objetos e personagens, é dessa vez retomada no plano temático; à relação entre infelicidade e graça, sobrepõe-se o esgotamento causado pela repetição. O resultado é a inversão da concepção de Bergson (1991, p.38) sobre a

3. Freud (1992 [1930]) proporciona uma boa metáfora dessa dinâmica - a ainda que ele próprio a reconheça como imperfeita - em “O mal estar na cultura”. 
repetição como algo cômico em si, o riso sendo provocado pela sugestão de que uma regra humana substitui a lei da natureza, como se existissem mecanismos escondidos controlando o que supomos contingencial ou simplesmente aleatório. Em contrapartida, Fim de Partida escancara a existência desses mecanismos, e o seu resultado não é o riso, pois o fio que o sustentaria é esticado até se romper. A existência de padrões recorrentes se desdobra por toda a peça, não se restringindo às referências textuais diretas ou à reincidência de enunciados específicos. Roger Blin, o diretor de sua primeira montagem, já notara que Beckett a concebia "como uma espécie de partitura musical. Quando uma palavra aparecia ou era repetida, quando Hamm chamava Clov, Clov deveria sempre vir, toda vez, do mesmo jeito, como uma frase musical vindo do mesmo instrumento no mesmo volume" (citado por GONTARSKI [ed.], 1992, p.xxi).

No mesmo sentido dessa ênfase na artificialidade do que é posto em cena, temos as recomendações de Beckett aos atores das montagens de Fim de Partida por ele mesmo dirigidas: nelas, palavra e gesto jamais devem coincidir, sendo separados por um pequeno intervalo que descarta qualquer possibilidade de representação naturalista, negando mesmo a preponderância da interioridade psicológica dos personagens em favor da plasticidade do contraste (citado por GONTARSKI [ed.], 1992, p.xix). Se essa descontinuidade poderia ser levada ao extremo, de forma a sugerir a presença de um dualismo análogo ao cartesiano ${ }^{4}$, a própria materialidade da junção entre texto e performance nos impede de tomála literalmente, pois seu funcionamento é estrutural, e não relativo a conteúdos: separados dos enunciados, os movimentos dos atores deles se distanciam, dissolvendo seu potencial de caracterização psicológica ou representação realista. O que sobra desse processo de esvaziamento de conteúdo é o procedimento como forma desprovida de significação, uma espécie de pulverização da pantomima de vaudeville, que se vê reduzida aos seus próprios destroços, pedaços de mímicas não mais capazes de provocar o riso. Visto pelo prisma de sua própria forma, o componente gestual da performance se integra à estrutura geral da peça, isto é, o estabelecimento de padrões de repetição que culminam em sua redução a restos - culturais, de acordo com Adorno - sem valor próprio.

4. Um exemplo-limite da tomada dessa hipótese como dado indiscutível pode ser encontrado em BERRETTINI (2004, p.133 e segs.); ainda que a autora em questão aborde nesse ponto Esperando Godot de acordo com essa lógica, suas considerações sobre Fim de Partida de forma alguma se distanciam de postulados como o da relação entre Vladimir e o intelecto, por meio do chapéu como símbolo, e Estragon e o corpo, por meio de suas botas. 
É também da perspectiva de sua dissecação que podemos tomar os demais procedimentos humorísticos reincidentes em Fim de Partida, que opõe a máxima resistência a essa tentativa de interpretação ao incorporar seu fracasso como parte de seu funcionamento interno, e nos leva de volta à afirmação de Hugh Kenner sobre as pistas de um sistema que não levam a lugar algum. Proponho, nesse ponto, que a teorização de Freud sobre o Witz, em suas relações com o cômico e o humor, pode ser vista de forma refratária na peça como forma de expandir a afirmação de Adorno (1985, p.66) de que nela "a medula foi sugada, tanto das piadas quanto das cores".

4 .

A teoria freudiana do Witz só pode ser transposta para o espaço interno do texto literário de forma altamente mediada, pois sua diferença com relação ao cômico e ao humor, para fazer uso de um termo que só surgiria posteriormente, é metapsicológica, dizendo respeito aos lugares do aparelho psíquico e suas inter-relações, e não se pode falar propriamente do inconsciente de Fim de Partida. Dito isso, a ênfase recai aqui nos locais de articulação de cada um desses processos como forma de abordar seus componentes estruturais, estes sim refratados na peça de formas diversas, cuja sobreposição talvez possibilite uma visão de conjunto de seus elementos. Para esse propósito, temos na piada contada por Nagg um momento privilegiado; ainda que longa, a passagem merece ser citada por completo:

NELL: Era porque me sentia feliz.

NAGG: Feliz coisa nenhuma, era por causa da minha história. A prova é que você ainda ri. Toda vez que eu conto.

NELL: [o Lago Como] era fundo, tão fundo... E a água transparente. Tão clara, tão limpa

NAGG: Deixa eu contar de novo. (Voz de narrador) Um gentleman (faz cara de inglês, remoa a sua) reparou na última hora que precisava de calças de riscas para as festas do fim do ano. Correu ao seu alfaiate que lhe tomou as medidas. (Voz de alfaiate) "Isso basta. Volte em quatro dias e estará pronta." Tudo bem. Quatro dias depois. (Voz de alfaiate) "Sorry, sir, volte em uma semana, cortei errado os fundilhos.” Tudo bem, essas coisas acontecem, fundilhos bem cortados são difíceis de acertar. Uma semana depois. (Voz de alfaiate) "Sinto muitíssimo, senhor, volte em dez dias, me enganei no cós." Tudo bem, que se há de fazer, o cós é essencial. Dez dias depois. (Voz de alfaiate) "Minhas mais sinceras desculpas. Volte em quinze dias, fiz uma bagunça na braguilha." Tudo bem, uma braguilha em ordem é estratégica. (Pausa. Voz normal) Conto cada vez pior, jamais contei tão 
mal. (Pausa. Melancólico) Naquele tempo contava muito melhor. (Pausa. Voz de narrador) Bom, pra encurtar o caso, as quaresmeiras já floriam e ele estraga as casas dos botões. (Expressão, depois voz do cliente) "Goddam, sir, não é possível, é um escândalo, um absurdo, não há Cristo que aguente! Em seis dias, ouviu bem, seis dias, nem mais nem menos, só seis dias, Deus fez o mundo. Sim senhor, o mundo, entendeu, o MUNDO! E o senhor não consegue acabar umas reles calças em três meses!" (Voz de alfaiate, escandalizado) "Mas Milord, Milord, olhe... (gesto de desprezo, com repugnância) ... o mundo... (pausa) ...e olhe... (gesto carinhoso, com orgulho) ... minhas CALÇAS!”

(Pausa. Olha para Nell, que permanence impassível com olhar vidrado, desata em um riso muito forçado e agudo, para bruscamente, estica-se em direção a Nell, retoma o riso.)

HAMM: Chega!

(Nagg sobressalta-se, para de rir.)

NELL: Uma água tão clara.

(Fim de Partida, 2002, pp.61-62)

A risada forçada de Nagg assinalada na rubrica soa tão teatral quanto as diferentes vozes por ele assumidas no andamento da piada, e essa teatralidade cria uma zona de indistinção entre o final de seu número e o espaço para a reação de sua platéia. Subvertendo a estrutura freudiana do Witz, a expressão impassiva de Nell e a rejeição de Hamm não possibilitam a Nagg que desfrute de sua própria piada, fazendo com que seu riso surja como paródia de si mesmo, e, em última instância, da própria platéia da peça, que se vê constrita entre as duas possibilidades de reação estéril já trazidas em cena. De acordo com Freud (2006 [1905]), o trabalho de elaboração formal funciona no Witz como uma espécie de suborno (o termo usado pelo autor é bestechen) que permite ao inconsciente se deixar ver, e a sanção daquele que ouve se dá por meio da descarga de energia materializada no riso, assinalando o sucesso do procedimento e permitindo ao produtor da piada que dela também desfrute. Contudo, o fracasso não se situa aqui no plano formal, mas nos espaços vazios que seriam ocupados pelas diferentes instâncias envolvidas em sua produção: transpondo a tópica freudiana para Fim de Partida, encontramos a rejeição de todo e qualquer conteúdo a contaminá-la como algo que, se não impossibilita o aparecimento do Witz, faz com que ele se comporte como uma forma oca, sua ausência de sentido subjacente sendo revertida em ausência de prazer. O espaço no qual seria permitido a Nell desfrutar da piada se encontra do lado de fora da peça, aludido nas referências a um passado cujo acesso é vedado, e, se acreditarmos em Nagg, ainda que sempre a tenha feito rir, sua insistência em recontar a piada não 
se justifica por seu resultado; ao contrário, ela escapa do circuito de produção do prazer, revelando-se como repetição compulsiva. Porém, isso não impede que haja na peça a existência de momentos que causem riso - e eles sem dúvida existem, sejam provocados na platéia ou nos personagens -, mas eles imprimem em sua ocorrência certo caráter espasmódico, como se fossem reflexos quase involuntários, sombras de uma graça esgotada.

Em seu estudo sobre a concepção freudiana do humor, Daniel Kupermann (2003, p.66 e segs) investiga a hipótese de que, na ausência de maiores desenvolvimentos sobre o conceito de sublimação na obra de Freud, o Witz serviria como seu modelo; trata-se, afinal, daquela que é a mais social dentre as formações do inconsciente, dependendo da sanção do Outro ${ }^{5}$ para que seu efeito se produza. De acordo com Kupermann (2003, p.68), tomar o Witz como sua matriz implicaria em conceber a sublimação como um processo de simbolização que não está calcado na deserotização dos objetos como forma de alcançar a satisfação pulsional - como seria inicialmente o caso, segundo o autor, para Freud -, mas, ao contrário, acena para a possibilidade de que tais objetos de satisfação erótica possam ser culturalmente partilhados. Tal concepção da sublimação - e, consequentemente, dos mecanismos gerais do humor - enfatiza seus componentes agregadores, resultando na primazia de Eros sobre a pulsão de morte, no sentido da formação de unidades cada vez maiores e mais complexas, para fazer uso dos termos de Mais além do princípio de prazer (FREUD, 1992 [1921]). Contudo, em Fim de Partida o acento recai sobre o lado destrutivo da dualidade pulsional, pois não há unificação, mas despedaçamento, seja por meio da repetição, seja por meio da impossibilidade de se partilhar qualquer coisa. Mesmo dessa perspectiva a peça não deixa de se antecipar mais uma vez à interpretação, pois uma forma degradada da relação entre humor e sublimação pode ser nela retroativamente inscrita por meio do paralelismo formal existente entre seus dois interlúdios narrativos, isto é, a piada de Nagg e a longa história contada por Hamm, da qual cito alguns trechos:

HAMM: [...] Naquele dia fazia, me lembro, um sol esplêndido, os heliômetros marcavam cinquenta. O sol já mergulhava no... na... entre os mortos. (Tom normal) Bonito isso. (Tom narrativo) Vamos, vamos, apresenta tua súplica, o tempo urge! (Tom normal) Ah, isso sim que é português! Enfim. (Tom narrativo) Foi então que ele criou coragem. É o meu filho, disse. [...]

5. Para a aproximação entre a terceira pessoa do chiste e o Outro lacaniano, cf. Lacan (1999), p.49 e segs. 
(Pausa) Naquele dia soprava, me lembro, um vento cortante, o anemômetro marcava cem. $\mathrm{O}$ vento arrancava os pinhos mortos e os varria... para longe. (Tom normal) Um pouco fraco isso. (Tom narrativo) Vamos logo, o que é que você quer? Ainda tenho que enfeitar o pinheiro. (Pausa) Em resumo, acabei compreendendo que ele queria pão para seu filho. Pão! Mais um pedinte! Pão? Olhe, eu não tenho pão, não me faz bem. Tudo bem. Cevada então? (Pausa. Tom normal) Assim está bom. [...]

(Pausa) No fim, me perguntou se eu consentiria em recolher também a criança - caso ela ainda estivesse viva. (Pausa) Era o momento que eu esperava. [...] (Pausado normal) Chega por hoje. (Pausa) Essa história não dura muito mais. [...]

NAGG: Meu caramelo!

CLOV: Tem um rato na cozinha.

(Fim de Partida, 2002, pp.95-96)

Tanto a piada de Nagg quanto a narrativa de Hamm são nomeadas por seus narradores como histórias, e seus procedimentos em muito se assemelham: em ambos os casos, tem-se a variação performática de diferentes tons, bem como a existência de pausas no andamento causadas pela intromissão de considerações estilísticas - Nagg comenta sua incompetência como piadista, e Hamm alterna auto-elogio e reprimenda com floreios descritivos sobre o clima. Seu encontro com o mendigo e o dilema sobre o acolhimento da criança insinuam-se com toda força como elementos pseudo-biográficos talvez apenas levemente reelaborados Beckett, quando perguntado sobre se a criança da história seria Clov ou não, respondeu "Simplesmente não sei" (citado por GONTARSKI, 1992, p.61). Ainda que seja talvez um exagero considerar a narrativa de Hamm como a versão que Fim de Partida apresenta de uma obra de arte, ela responde ao mecanismo sublimatório acima esboçado por meio de sua parodização, especialmente se tomarmos essa noção no sentido adorniano (1985, p.67) do uso de formas na época de sua impossibilidade. Seu fracasso fica claro pelo resultado idêntico das investidas de Nagg e Hamm: não apenas o momento de satisfação não se realiza, mas também não existiria qualquer possibilidade de compartilhá-lo, já que ambas as narrativas seguem ignoradas por seus ouvintes. Porém, se o recurso à paródia só pode ser percebido aqui por meio de sua reconstrução a posteriori, sua existência é escancarada em diversos níveis da peça: há nela a referência distorcida a versos shakespeareanos, como "Meu reino por um lixeiro" (Fim de Partida, 2002, p.62), e seu próprio protagonista assume declaradamente a posição de herói trágico, deturpando sua pretensão de grandeza por meio da auto-consciência de seu status ficcional, dando-se o direito a um monólogo dramático de abertura 
entrecortado por bocejos, onde assume que seu sofrimento é absoluto e incomparável. Nos termos de sua estrutura, mesmo as convenções mais basais da dramaturgia são parodiadas, conforme notado por Adorno, para quem em Fim de Partida "as três unidades aristotélicas são mantidas, mas o drama em si perece" (1985, p.67). O resultado desse procedimento é uma inversão paradoxal do estatuto do cômico freudiano: se, de acordo com o autor, o cômico se dá pelo estabelecimento de uma comparação entre duas pessoas que se mostra desfavorável para aquele de quem se ri, a escassez de material dramático e a desolação do que é posto em cena acabam por situar o objeto do pouco riso que resta em uma posição de superioridade inesperada, cristalizando o peso da tradição com a máxima força por meio da violência com que a ela se dirige o ataque derrisório.

Em um ensaio de 1927 intitulado "O humor", Freud (1992, p.155-162) retoma um exemplo surgido na parte final de seu livro de 1905 como forma de abordar o humor de acordo a divisão do aparelho psíquico entre isso, eu e supereu: um condenado, dirigindo-se em uma segunda-feira ao local em que será enforcado, encontra forças para exclamar "É, a semana está começando muito bem!". De acordo com o autor, o efeito dessa frase prescinde da estrutura ternária do Witz, e mesmo da comparação cômica entre duas pessoas, pois seu funcionamento é circunscrito a variações de investimento no aparelho psíquico do autor do dito humorístico: a energia libidinal é aqui retirada do eu e sobreinvestida no supereu como forma de produzir um distanciamento com relação à situação adversa que se enfrenta, como se ela fosse irrelevante - Freud chega a afirmar que seu funcionamento é análogo ao gesto de um pai a proteger uma criança impotente. Por sua vez, em Fim de Partida as tentativas de se tomar distância não se restringem apenas àquilo que é adverso, ainda que seu propósito seja totalmente desvirtuado: as frequentes pausas de Hamm no andamento de sua história produzem simultaneamente seu próprio distanciamento com relação ao material por ele narrado e a anestesia por parte de seus ouvintes - e mesmo da platéia - de qualquer possibilidade de reação ao conteúdo emocional de sua história, o mesmo se dando com relação à piada de Nagg. A série de referências metateatrais nas falas de Hamm produzem também efeito semelhante, a metalinguagem minando qualquer chance de grandeza trágica por meio de sua pretensão autodeclarada - e essa autoconsciência, aludida incontáveis vezes ao longo da peça, adiciona outra nota de indeterminação ao arremedo de enredo encenado, o que leva Hugh Kenner (1973, p.155) a concluir que seus poucos acontecimentos são "repetidos e repetíveis".

Contudo, há ainda outro tipo de distanciamento, situado ao nível mais fundamental de sua estrutura, que a princípio soa como um 
anacronismo avesso a um autor vanguardista como Beckett, mas de nossa perspectiva assume uma significação inesperada: trata-se da quarta parede, cuja existência é afirmada pelo próprio autor (cf. GONTARSKI, 1992, p.xxi), que separa a ação posta em cena do público do teatro. Na leitura aqui produzida, o distanciamento estabelecido no plano formal desvela-se finalmente como uma tentativa de proteção, tornando-se literalmente a quarta parede do abrigo de Hamm, e desse modo levando a resistência de Fim de Partida a tudo o que lhe é externo - incluindo, aqui, a própria realidade - até o limite do contraste entre a força de sua recusa e o pouco que resta a ser protegido. Visto de dentro da peça, o destino do enforcado de Freud não é o pior possível: se o humor pode fazer frente mesmo à morte incontornável, contra o esgotamento total de um mundo em ruínas ele é capaz apenas de produzir espasmos.

\section{REFERÊNCIAS BIBLIOGRÁFICAS}

ADORNO, Theodor. Trying to Understand Endgame. In: BLOOM, Harold (ed.). Modern Critical Views - Samuel Beckett. Philadelphia: Chelsea House Publishers, 1985, p.5181.

BECKETT, Samuel. Watt. Londres: John Calder, 1976.

. The Theatrical Notebooks of Samuel Beckett-Vol. 2: Endgame (ed. por GONTARSKI, Stanley). Londres: Faber \& Faber, 1992.

. Fim de Partida (trad. de Fábio de Souza Andrade). São Paulo: Cosac Naify, 2002. . Endgame. In: The Complete Dramatic Works. Londres: Faber \& Faber, 2006.

BERGSON, Henri. O riso: ensaio sobre a significação do cômico (trad. de Miguel Serras Pereira). Lisboa: Relógio d'Água, 1991.

BERRETTINI, Célia. Samuel Beckett - Escritor plural. São Paulo: Perspectiva, 2004.

COHN, Ruby. Back to Beckett. Princeton: Princeton University Press, 1973.

ESSLIN, Martin. O Teatro do Absurdo (trad. de Bárbara Heliodora). Rio de Janeiro: Zahar Editores, 1968.

FLETCHER, John. Faber Critical Guides - Samuel Beckett. London: Faber and Faber, 2000.

FREUD, Sigmund. El chiste y su relación con lo inconciente (1905). In: Obras completas (trad. de José Etcheverry). Buenos Aires: Amorrortu editores, 2006, vol.8. . Más allá del principio de placer (1921). In: Obras completas (trad. de José Etcheverry). Buenos Aires: Amorrortu editores, 1992, vol.18.

. El malestar en la cultura (1930 [1929]). In: Obras completas (trad. de José Etcheverry). Buenos Aires: Amorrortu editores, 1992, vol.21, p.57-140. 
. "El humor (1927)". In: Obras completas (trad. de José Etcheverry). Buenos Aires: Amorrortu editores, 1992, vol.21, p.155-162.

KENNER, Hugh. Samuel Beckett - A Critical Study. New York: Grove Press, 1973. . A Reader's Guide to Samuel Beckett. Syracuse: Syracuse University Press, 1996.

KNOWLSON, James. Damned to fame - The Life of Samuel Beckett. Londres: Bloomsbury, 1996.

KUPERMANN, Daniel. Ousar rir - Humor, criação e psicanálise. Rio de Janeiro: Civilização Brasileira, 2003.

LACAN, Jacques. O Seminário, livro 5 - As formações do inconsciente (trad. de Vera Ribeiro). Rio de Janeiro: Zahar, 1999.

Artigo do jornal satírico The Onion:

http://www.theonion.com/articles/scholars-discover-23-blank-pages-that-may-aswell,1946/ (acessado em 21/o1/2011) 
